\title{
Impact of diabetes on COVID-19-related in-hospital mortality: a retrospective study from Northern Italy
}

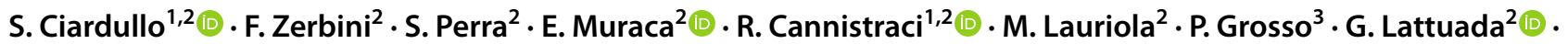 \\ G. Ippoliti ${ }^{2} \cdot$ A. Mortara ${ }^{4} \cdot$ G. Manzoni ${ }^{2} \cdot$ G. Perseghin ${ }^{1,2}$
}

Received: 5 June 2020 / Accepted: 31 July 2020 / Published online: 10 August 2020

(c) The Author(s) 2020

\begin{abstract}
Purpose The purpose of this study was to evaluate the impact of pre-existing diabetes on in-hospital mortality in patients admitted for Coronavirus Disease 2019 (COVID-19).

Methods This is a single center, retrospective study conducted at Policlinico di Monza hospital, located in the Lombardy region, Northern Italy. We reviewed medical records of 373 consecutive adult patients who were hospitalized with COVID19 between February 22 and May 15, 2020. Data were collected on diabetes status, comorbid conditions and laboratory findings. Multivariable logistic regression was performed to evaluate the effect of diabetes on in-hospital mortality after adjustment for potential confounding variables.

Results Mean age of the patients was $72 \pm 14$ years (range 17-98), 244 (65.4\%) were male and 69 (18.5\%) had diabetes. The most common comorbid conditions were hypertension (237 [64.8\%]), cardiovascular disease (140 [37.7\%]) and malignant neoplasms (50 [13.6\%]). In-hospital death occurred in 142 (38.0\%) patients. In the multivariable model older age (Relative Risk [RR] 1.06 [1.04-1. 09] per year), diabetes (RR 1.56 [1.05-2.02]), chronic obstructive pulmonary disease (RR 1.82 [1.13-2.35]), higher values of lactic dehydrogenase and C-reactive protein were independently associated with in-hospital mortality.
\end{abstract}

Conclusion In this retrospective single-center study, diabetes was independently associated with a higher in-hospital mortality. More intensive surveillance of patients with this condition is to be warranted.

Keywords Diabetes $\cdot$ COVID-19 $\cdot$ Coronavirus $\cdot$ Mortality $\cdot$ SARS-CoV-2

\begin{tabular}{ll}
\multicolumn{2}{l}{ Abbreviations } \\
CKD & Chronic kidney disease \\
COPD & Chronic obstructive pulmonary disease \\
CVD & Cardiovascular disease \\
COVID-19 & Coronavirus disease 2019
\end{tabular}

G. Perseghin

gianluca.perseghin@ policlinicodimonza.it;

gianluca.perseghin@unimib.it

1 Department of Medicine and Surgery, Università degli Studi di Milano Bicocca, Milan, Italy

2 Department of Medicine and Rehabilitation, Policlinico di Monza, Via Modigliani 10, 20900 Monza, MB, Italy

3 Department of Anesthesiology and Intensive Care, Policlinico di Monza, Monza, Italy

4 Department of Clinical Cardiology, Policlinico di Monza, Monza, Italy

\section{Introduction}

Coronavirus Disease 2019 (COVID-19), caused by severe acute respiratory syndrome coronavirus 2 (SARS-CoV-2) emerged in Wuhan in December 2019. The disease rapidly spread throughout the world and was announced as a global pandemic by the World Health Organization. Italy was among the first and most severely affected countries and by the time we are writing (end of May 2020) 225.549 cases and 30.332 deaths occurred, most of which in the Northern part of the country, with the Lombardy region accounting for more than a third of cases and half deaths (https://www. epicentro.iss.it).

Since the infection can have a broad range of severity going from an asymptomatic state, to symptoms similar to those of the common cold, to severe forms of interstitial pneumonia that need urgent medical attention, knowledge of risk factors for adverse clinical outcomes would be of great utility [1]. It soon became apparent that age and number of 
comorbidities were crucial to predict the need of intensive care unit (ICU) admission and death [2].

Diabetes is common among patients who die from COVID-19, with data from Italy showing a prevalence of approximately 30\% [3]. Moreover, it is well known that patients with diabetes have higher risk of infections because of alterations in the immune response [4]. Nonetheless, it remains controversial whether diabetes could be considered an independent risk factor for greater severity of illness and death, with some studies showing a detrimental effect [5-7] and others a neutral influence [8-10], also depending on adjustment for confounding variables. Moreover, the vast majority of the published literature comes from China, and little is known in western countries and Italy in particular [11].

Therefore, the present study was conceived to obtain more conclusive information on the relationship between a history of diabetes and the risk of in-hospital mortality.

\section{Methods}

\section{Study sample}

This single center retrospective study was conducted at Policlinico di Monza hospital in Monza, a 240-bed community based hospital designated to treat patients with COVID19 , located in the Lombardy region, Italy. We included all patients aged $\geq 18$ years who were admitted from 22 February 2020 and experienced a definite outcome (either in-hospital death or discharge) as of 15 May 2020. These patients have not been reported before and represent a large spectrum of disease severity, including critically ill patients treated in the ICU.

COVID-19 cases were defined according to a positive result on real-time reverse transcriptase-polymerase chain reaction (RT-PCR) of nasopharyngeal or oropharyngeal swab specimens and/or clinically by the presence of typical signs and symptoms, exposure to known affected individuals and radiographic findings consistent with interstitial pneumonia.

The investigations were conducted in accordance with the current Declaration of Helsinki. The study was approved by the local ethical committee and the requirement for informed consent was waived because of the retrospective design and the ongoing public health emergency.

\section{Procedures and definitions}

Using electronical medical records, we reviewed data related to demographic variables (age, gender, and occupational status), previous medical history and comorbidities and prescription medications. Date of admission, total hospital length of stay, presenting symptoms (including fever, cough, dyspnea, diarrhea and conjunctivitis), plasma and serum based biomarkers drawn within $48 \mathrm{~h}$ of hospital admission or transfer from different hospitals, and radiographic findings at presentation were also reviewed by a team of experienced clinicians. Routine laboratory examinations included a complete blood cell count, liver (aspartate aminotransferase, [AST] and alanine aminotransferase, [ALT]) and renal function testing, lactic dehydrogenase (LDH), creatine kinase and c-reactive protein (CRP).

Fever was defined as an axillary temperature $\geq 37.5^{\circ} \mathrm{C}$. Medical comorbidities of interest included diabetes, hypertension, previous cardiovascular disease (CVD), a composite of coronary artery disease, stable angina, stroke and transient ischemic attack, previous or active malignant neoplasia, chronic obstructive pulmonary disease (COPD), asthma, neurological conditions (such as dementia and parkinsonism), chronic kidney disease (CKD) and hematological disorders.

\section{Statistical analysis}

Data are expressed as means \pm standard deviation (SD) for continuous variables or as numbers and percentages for categorical variables. Analyses were performed using the SPSS software (version 24.0; SPSS, Chicago, IL). Normal distribution was assessed by the d'Agostino D-normality test [12] and skewed data were properly transformed before the analysis.

Categorical variables were compared by Pearson chisquare test. Independent sample $T$-test or Mann-Whitney test were used to compare groups. Levene's test was performed to assess equality of variance. The percentage of missing values was equal to $9.12 \%$ and a listwise deletion approach was used to manage missing data.

Binomial logistic regression analysis was performed to ascertain the effects of several variables on the likelihood of mortality. Linearity of the continuous variables was assessed via the Box-Tidwell procedure and multi-collinearity was tested.

Given the number of deaths in our population, we included eleven independent variables in our model to avoid overfitting. Age and gender were included as males and older individuals were shown to have a higher mortality risk in previous studies [13]. Beside diabetes, we included other comorbidities that were significantly more common among deceased participants, such as hypertension, CVD, COPD and CKD. Finally, laboratory exams that were previously reported as predictive of severe disease or distributed unequally between discharged and deceased patients were included (platelet count, LDH, CRP and creatinine). Despite being associated with both diabetes and mortality, we did not 
include AST levels in the multivariate models as they were missing in a substantial number of patients.

Due to missing data, analysis was carried out in a subgroup of 339 subject from the 371 of the entire population.

The False Discovery Rate approach was used to control for multiple comparisons and the Benjamini and Hochberg procedure was assessed to minimize possible type I errors using a $q$ value equal to 0.10 [14]; adjusted $p$ values were reported.

A $p$ value $\leq 0.05$ was considered to be significant.

\section{Results}

\section{Population characteristics}

Of the 373 patients included in the study 129 were females $(34.6 \%)$ and 244 were males $(65.4 \%)$. Mean age was $72 \pm 14$ years (range 17-98) and only 51 individuals (13.7\%) were younger than 55.319 patients $(85.5 \%)$ had a positive RT-PCR result and the remaining 54 (14.5\%) tested negative and were diagnosed clinically. Apart from being significantly older than confirmed cases ( 76 vs 71 years, $p=0.12$ ), patients with clinically diagnosed COVID-19 exhibited similar clinical features and comorbidities.

As shown in Table 1, most patients had comorbidities, the most common being hypertension (64.8\%), followed by CVD (37.7\%) and 69 patients had diabetes (prevalence of $18.5 \%)$. The most common presenting symptom was fever $(82.6 \%)$, followed by dyspnea (71.3\%) and cough (39.1\%). Non-respiratory symptoms and signs, such as diarrhea and conjunctivitis were much less commonly reported. 58 patients were admitted to the ICU, of which 14 (24.1\%) were transferred from other hospitals on mechanical ventilation.

\section{Comparison between deceased and discharged patients}

In total 142 patients (38.1\%) died. As expected, patients who experienced in-hospital death were older (78 vs 68 years, $p<0.001)$ and had a higher prevalence of most comorbidities including CVD (46.4\% vs $32.5 \%, p=0.007)$ and hypertension ( 78.1 vs $56.8 \%, p<0.001$ ), whereas only a trend was found for diabetes ( 23.2 vs $15.6 \%, p=0.064$ ) and no significant differences were found in gender distribution. Cough was a more common presenting symptom among discharged patients ( $45.9 \%$ vs $28.2 \%, p=0.001$ ), whereas dyspnea was more frequently encountered in those who died $(85.9 \%$ vs $62.3 \%, p<0.001)$.

Deceased patients also exhibited less favorable laboratory features at the time of hospital admission, including lower lymphocyte $\left(0.91\right.$ vs $\left.1.13 \times 10^{9} / 1, p<0.001\right)$ and platelet count (196 vs $\left.242 \times 10^{9} / 1, p<0.001\right)$ and higher CRP (141 vs $79 \mathrm{mg} / \mathrm{l}, p<0.001)$ and LDH (822 vs $527 \mathrm{U} / \mathrm{l}$ ) values (Fig. 1).

\section{Comparison between patients with and without diabetes}

Features of the entire population according to diabetes status are shown in Table 2. No significant differences were found between patients with and without diabetes with regards to sex, age (74 vs 71 years, $p=0.518$ ) and frequency of symptoms at hospital admission.

As expected both hypertension and CKD were more common among patients with diabetes, but no differences were found in the prevalence of COPD, cancer and CVD. Most laboratory features were not different between groups, except for lower AST, ALT and hemoglobin values and a trend towards a higher creatinine in patients with diabetes.

We found a significant difference in length of stay (LOS) between discharged and deceased patients $(16.1 \pm 9.7$ vs $10.7 \pm 11.0$ days respectively, $p<0.001$ ). However no significant difference in LOS was found between non-diabetic and diabetic patients $(14.3 \pm 10.8$ vs $12.8 \pm 9.2$ days respectively, $p=0.397$ ) even when the analysis was conducted in discharged and deceased patients separately $(p=0.934$ and $p=0.520$, respectively).

As far as antidiabetic treatment regimen was concerned $40.6 \%$ of patients with diabetes were on insulin, $43.5 \%$ on oral antidiabetic drugs and $15.9 \%$ were on non-pharmacological treatment. Finally, steroid therapy was not used differently in patients with and without diabetes $(11.8 \%$ and $13.0 \%$ respectively, $p=0.782$ ).

In the multivariable logistic regression model (Table 3) older age (Relative Risk [RR] 1.06 [95\% confidence interval (CI) 1.04-1.09] per 1 year increase, $p<0.001$ ), COPD (RR 1.82 [95\% CI 1.13-2.35]), diabetes (RR 1.56 [95\% CI 1.06-2.02]), higher levels of CRP (RR 1.70 [95\% CI 1.36-2.07] per standard deviation increase, $p<0.001)$ and higher concentrations of LDH (RR 2.14 [95\% CI 1.65-2.68] per standard deviation increase, $p<0.001$ ) were independently associated with in-hospital mortality, whereas sex, CKD, CVD and hypertension were not. Mortality rate in patients included in the multivariable model was not different from overall mortality $(36.2 \%$ vs $38 \%, p=0.22)$.

Finally, in a model considering only demographic variables and pre-existing comorbidities, increasing age and male sex were significantly associated with higher mortality (Table 4).

\section{Discussion}

In the present study we show that among patients hospitalized for COVID-19 in a single center in Northern Italy, a history of diabetes was associated with an increased mortality 
Table 1 Demographic and laboratory features of patients with diagnosed COVID-19 segregated by mortality

\begin{tabular}{|c|c|c|c|c|}
\hline & All patients & Discharged & Deceased & $p$ value \\
\hline$N$ (female/male) & $373(129 / 244)$ & $231(146 / 85)$ & $142(44 / 98)$ & 0.252 \\
\hline Age (years) & $72 \pm 14$ & $68 \pm 14$ & $78 \pm 10$ & $<0.001$ \\
\hline$\leq 55(\%)$ & $13.7 \%(51)$ & $19.9 \%(46)$ & $3.5 \%(5)$ & $<0.001$ \\
\hline $56-75(\%)$ & $37.8 \%(141)$ & $44.2 \%(102)$ & $27.5 \%(39)$ & \\
\hline $76-85(\%)$ & $35.4 \%(132)$ & $29.0 \%(67)$ & $45.8 \%(65)$ & \\
\hline$>85(\%)$ & $13.1 \%(49)$ & $6.9 \%(16)$ & $23.2 \%(33)$ & \\
\hline Intensive Care Unit (\%) & $15.5 \%(58)$ & $6.5 \%(15)$ & $30.3 \%(43)$ & $<0.001$ \\
\hline \multicolumn{5}{|l|}{ Comorbidities } \\
\hline Diabetes $(\%)$ & $18.5 \%(69)$ & $15.6 \%(36)$ & $23.2 \%(33)$ & 0.064 \\
\hline Hypertension (\%) & $64.8 \%(237)$ & $56.8 \%(130)$ & $78.1 \%(107)$ & $<0.001$ \\
\hline CKD $(\%)$ & $12.9 \%(48)$ & $9.5 \%(22)$ & $18.3 \%(26)$ & 0.014 \\
\hline Tumors (\%) & $13.6 \%(50)$ & $12.2 \%(28)$ & $15.8 \%(22)$ & 0.320 \\
\hline Cardiovascular diseases (\%) & $37.7 \%(140)$ & $32.5 \%(75)$ & $46.4 \%(65)$ & 0.007 \\
\hline $\operatorname{COPD}(\%)$ & $10.6 \%(39)$ & $6.5 \%(15)$ & $17.4 \%(24)$ & 0.001 \\
\hline \multicolumn{5}{|l|}{ Symptoms at admission } \\
\hline Cough $(\%)$ & $39.1 \%(146)$ & $45.9 \%(106)$ & $28.2 \%(40)$ & 0.001 \\
\hline Dyspnea (\%) & $71.3 \%(266)$ & $62.3 \%(144)$ & $85.9 \%(122)$ & $<0.001$ \\
\hline Fever $\left(\geq 37.5^{\circ} \mathrm{C}\right)(\%)$ & $82.6 \%(308)$ & $82.3 \%(190)$ & $83.1 \%(118)$ & 0.834 \\
\hline Diarrhea (\%) & $4.8 \%(18)$ & $6.1 \%(14)$ & $2.8 \%(4)$ & 0.159 \\
\hline Conjunctivitis (\%) & $0.8 \%(3)$ & $0.4 \%$ & $1.4 \%(2)$ & 0.306 \\
\hline \multicolumn{5}{|l|}{ Laboratory features at admission } \\
\hline White blood cells $\left(10^{9} / 1\right)$ & $8.00 \pm 4.02$ & $7.72 \pm 3.99$ & $8.46 \pm 4.05$ & 0.019 \\
\hline Lymphocytes $\left(10^{9} / 1\right)$ & $1.05 \pm 1.12$ & $1.13 \pm 0.81$ & $0.91 \pm 1.49$ & $<0.001$ \\
\hline Neutrophils $\left(10^{9} / 1\right)$ & $6.33 \pm 3.7$ & $5.91 \pm 3.75$ & $7.02 \pm 3.52$ & $<0.001$ \\
\hline Hemoglobin (g/dl) & $12.83 \pm 2.04$ & $12.89 \pm 1.98$ & $12.74 \pm 2.14$ & 0.382 \\
\hline Platelets $\left(10^{9} / 1\right)$ & $225 \pm 107$ & $242 \pm 114$ & $196 \pm 87$ & $<0.001$ \\
\hline Creatinine (mg/dl) & $1.2 \pm 1.01$ & $1.05 \pm 0.98$ & $1.46 \pm 1$ & $<0.001$ \\
\hline $\operatorname{AST}(\mathrm{U} / \mathrm{l})$ & $50 \pm 51$ & $45 \pm 46$ & $57 \pm 59$ & $<0.001$ \\
\hline $\operatorname{ALT}(\mathrm{U} / \mathrm{l})$ & $44 \pm 49$ & $46 \pm 55$ & $39 \pm 35$ & 0.319 \\
\hline CRP (mg/l) & $103 \pm 82$ & $79 \pm 71$ & $141 \pm 85$ & $<0.001$ \\
\hline LDH (U/l) & $636 \pm 335$ & $527 \pm 234$ & $822 \pm 397$ & $<0.001$ \\
\hline D-dimer (ng/ml) & $2634 \pm 8313$ & $1463 \pm 3543$ & $4781 \pm 12,922$ & $<0.001$ \\
\hline $\mathrm{CPK}(\mathrm{U} / \mathrm{l})$ & $237 \pm 319$ & $174 \pm 226$ & $312 \pm 391$ & $<0.001$ \\
\hline ASTtoALTratio & $1.38 \pm 0.68$ & $1.22 \pm 0.62$ & $1.68 \pm 0.68$ & $<0.001$ \\
\hline
\end{tabular}

Pearson $\chi^{2}$ test, independent sample $T$-test or Mann-Whitney test was used to compare groups

$C K D$ chronic kidney disease, COPD chronic obstructive pulmonary disease, AST aspartate aminotransferase, $A L T$ alanine aminotransferase, $C P R$ C-reactive protein, $L D H$ lactic dehydrogenase, $C P K$ creatine phosphokinase risk, which was independent from several confounding factors and comorbidities.

An association between diabetes, glycemic control and COVID-19 outcomes has been previously suggested in several studies, mostly coming from China $[15,16]$. It is important to note, however, that clinical features of patients reported in previous studies were different from ours on several aspects and that adjustment for confounding variables was heterogeneous [8, 17]. Finally, different endpoints were considered, going from radiographic findings to ICU admission to in-hospital mortality [7]. Our population was significantly older compared with that of most studies from China with a mean age of $\sim 70$ years instead of $\sim 60$. As a consequence, most comorbidities were also more common, including hypertension, diabetes and CVD. Given the high burden of comorbid conditions in our population we made an effort to control for factors that were more likely to influence prognosis and still identified diabetes as a factor that could moderately increase the risk of in-hospital mortality.

It should be noted that our study was performed in a hospital setting including patients managed in the ICU and therefore represents the severe spectrum of COVID-19 
Fig. 1 Biochemical features of the study population segregated according to in-hospital death or discharge a Lymphocyte count; b Platelet count; c Lactic dehydrogenase; d C-reactive protein
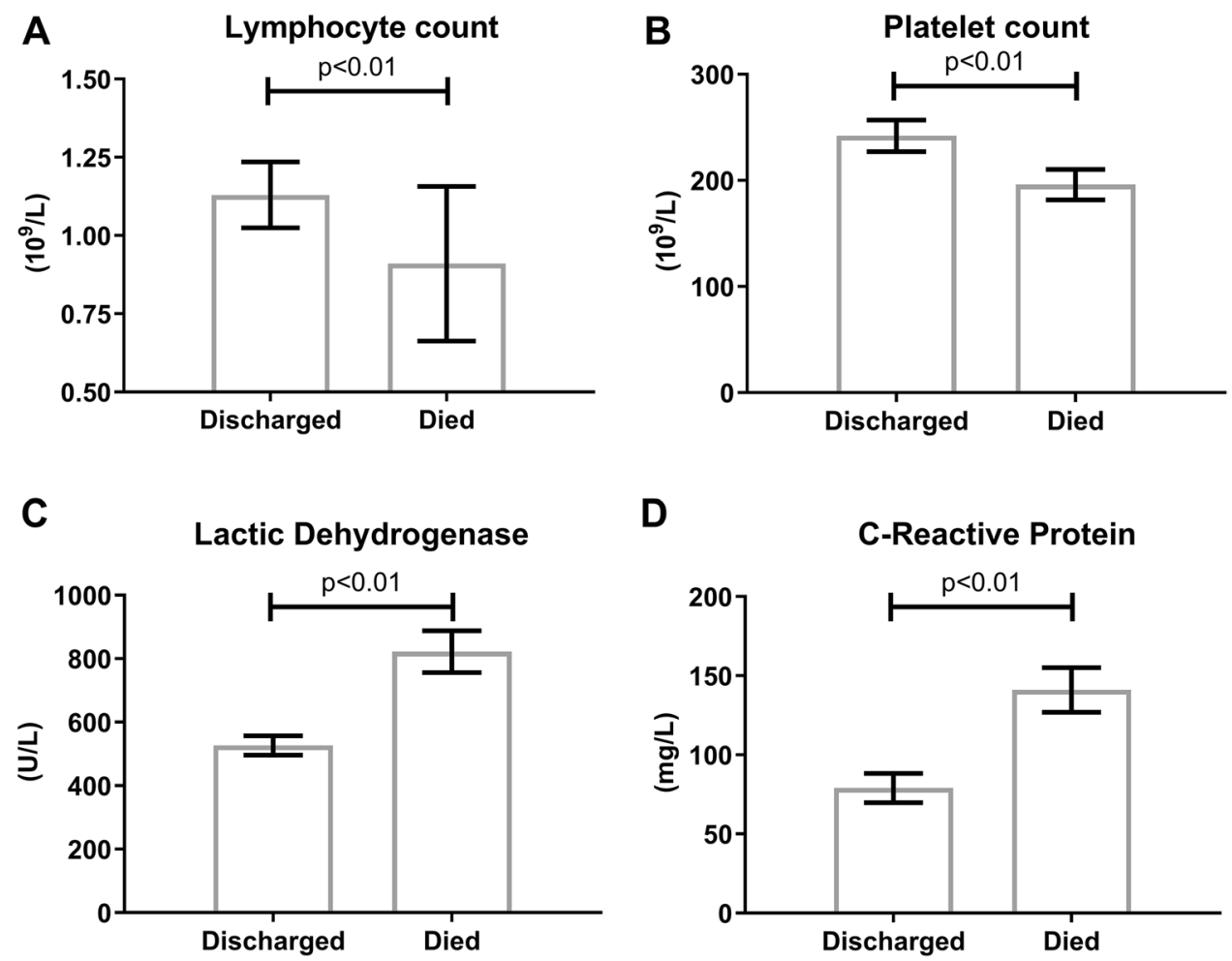

affecting frail patients. As a result, while the mean age of our population was significantly higher when compared to Italian data from the Istituto Superiore di Sanità on all infected patients (62 years), the features of deceased patients were similar (median age of 80 years and a prevalence of diabetes of $\sim 30 \%)$.

Several explanations of the association between diabetes and worse clinical outcome can be proposed [18]. In general, patients with diabetes are more susceptible to a wide range of infections because of alterations in neutrophil chemotaxis, cytokine production and impaired T-cell responses as a consequence of hyperglycemia [19-21]. With this regard a recent non peer-reviewed study clearly showed that diabetic patients experienced a delayed clearance of SARS-CoV-2 [22].

A possible role of antidiabetic therapy cannot be excluded and special interest has been devoted to dipeptidyl-peptidase 4 (DPP4) inhibitors, as DPP4 was one of the receptors involved in the infection from a related coronavirus (Middle East Respiratory Syndrome-Coronavirus). To date, evidence of a possible role of this class of drugs on clinical outcomes is limited to our knowledge to a small study showing a neutral effect [23]. On the same lines sodium-glucose transporter 2 (SGLT2) inhibitors may exert a positive effect in these patients by raising hematocrit, reducing intracellular sodium and calcium and reduce inflammation [24]. A recent study, however, did not show any benefits in terms of length of hospital stay in Italian patients with COVID-19
[25]. Unfortunately, the number of patients with diabetes in our cohort was not large enough to evaluate a possible contribution of specific anti-diabetic drugs.

Finally, patients with diabetes often have comorbid hypertension, heart failure or proteinuria and are frequently treated with blockers of the renin-angiotensin-aldosterone system. Since angiotensin converting enzyme 2 participates in SARS-CoV-2 cell entry process, it was hypothesized that these drugs could increase the risk of infection or worsen the prognosis related to COVID-19. A recent study from the Lombardy region, however, disproved this theory [26].

Some previous studies suggested that a history of hypertension and CVD had a detrimental effect on COVID-19 severity and death. We believe that older age and a more complex set of comorbidities in our patients compared with previous studies may modulate the effect of these conditions on survival. Our data align, on the other hand, with recent results obtained from a multicenter Italian study investigating this issue, which showed that diabetes, but not hypertension or CAD were associated with death [27].

The present study has several limitations that need to be addressed. First, the lack of data on anthropometric parameters in most patients did not allow us to calculate body mass index and to control for the impact of obesity on the primary outcome. Second, we did not have data on glycemic control for most subjects and cannot infer whether any difference in clinical outcomes existed between controlled and uncontrolled diabetes. Third, given 
Table 2 Demographic and laboratory features of patients with diagnosed COVID-19 segregated by T2DM

\begin{tabular}{|c|c|c|c|}
\hline & No diabetes & Diabetes & $p$ value \\
\hline$N$ (female/male) & $304(108 / 196)$ & $69(21 / 48)$ & 0.422 \\
\hline Age (years) & $71 \pm 14$ & $74 \pm 11$ & 0.518 \\
\hline$\leq 55(\%)$ & $15.5 \%(47)$ & $5.8 \%(4)$ & 0.148 \\
\hline $56-75(\%)$ & $36.5 \%(111)$ & $43.5 \%(30)$ & \\
\hline $76-85(\%)$ & $34.5 \%(105)$ & $39.1 \%(27)$ & \\
\hline$>85(\%)$ & $13.5 \%(41)$ & $11.6 \%(8)$ & \\
\hline Intensive care unit (\%) & $14.8 \%(45)$ & $18.8 \%(13)$ & 0.403 \\
\hline In-hospital death & $35.9 \%(109)$ & $47.8 \%(33)$ & 0.064 \\
\hline \multicolumn{4}{|l|}{ Comorbidities } \\
\hline Hypertension (\%) & $60.9 \%(182)$ & $82.1 \%(55)$ & 0.001 \\
\hline CKD $(\%)$ & $10.5 \%(32)$ & $23.2 \%(16)$ & 0.005 \\
\hline Tumors (\%) & $14.3 \%(43)$ & $10.1 \%(7)$ & 0.359 \\
\hline $\begin{array}{l}\text { Cardiovascular diseases } \\
(\%)\end{array}$ & $35.8 \%(108)$ & $46.4 \%(32)$ & 0.101 \\
\hline COPD $(\%)$ & $10.4 \%(31)$ & $11.6 \%(8)$ & 0.765 \\
\hline \multicolumn{4}{|l|}{ Symptoms at admission } \\
\hline Cough $(\%)$ & $39.8 \%(121)$ & $36.2 \%(25)$ & 0.583 \\
\hline Dyspnea (\%) & $70.7 \%(215)$ & $73.9 \%(51)$ & 0.597 \\
\hline Fever $\left(\geq 37.5^{\circ} \mathrm{C}\right)(\%)$ & $83.2 \%(253)$ & $79.7 \%(55)$ & 0.487 \\
\hline Diarrhea (\%) & $5.3 \%(16)$ & $2.9 \%(2)$ & 0.408 \\
\hline Conjunctivitis (\%) & $0.7 \%(2)$ & $1.4 \%(1)$ & 0.506 \\
\hline \multicolumn{4}{|c|}{ Laboratory features at admission } \\
\hline White blood cells $\left(10^{9} / 1\right)$ & $7.91 \pm 4.11$ & $8.04 \pm 3.60$ & 0.130 \\
\hline Lymphocytes $\left(10^{9} / 1\right)$ & $1.01 \pm 1.08$ & $1.21 \pm 1.27$ & 0.217 \\
\hline Neutrophils $\left(10^{9} / 1\right)$ & $6.29 \pm 3.84$ & $6.51 \pm 3.03$ & 0.200 \\
\hline Hemoglobin (g/dl) & $12.94 \pm 2.06$ & $12.35 \pm 1.87$ & 0.040 \\
\hline Platelets $\left(10^{9} / 1\right)$ & $228 \pm 111$ & $208 \pm 84$ & 0.306 \\
\hline Creatinine (mg/dl) & $1.18 \pm 1.05$ & $1.30 \pm 0.79$ & 0.075 \\
\hline AST (U/l) & $51 \pm 47$ & $44 \pm 67$ & 0.004 \\
\hline $\operatorname{ALT}(\mathrm{U} / \mathrm{l})$ & $46 \pm 51$ & $33 \pm 35$ & 0.008 \\
\hline $\mathrm{CRP}(\mathrm{mg} / \mathrm{l})$ & $104 \pm 84$ & $98 \pm 74$ & 0.730 \\
\hline LDH (U/l) & $621 \pm 304$ & $699 \pm 439$ & 0.289 \\
\hline D-dimer (ng/ml) & $2372 \pm 7693$ & $3759 \pm 10,601$ & 0.233 \\
\hline CPK (U/l) & $253 \pm 349$ & $184 \pm 183$ & 0.490 \\
\hline AST to ALT ratio & $1.36 \pm 0.67$ & $1.47 \pm 0.71$ & 0.254 \\
\hline \multicolumn{4}{|l|}{ Anti-diabetic therapy } \\
\hline Non-pharmacologic & $0.0 \%$ & $15.9 \%$ & - \\
\hline Oral antidiabetic drugs & $0.0 \%$ & $43.5 \%$ & - \\
\hline Insulin only & $0.0 \%$ & $31.9 \%$ & - \\
\hline Combined therapy & $0.0 \%$ & $8.7 \%$ & - \\
\hline
\end{tabular}

Pearson $\chi^{2}$ test, independent sample $T$-test or Mann-Whitney test was used to compare groups

$C K D$ chronic kidney disease, $C O P D$ chronic obstructive pulmonary disease, $A S T$ aspartate aminotransferase, $A L T$ alanine aminotransferase, $C P R$ C-reactive protein, $L D H$ lactic dehydrogenase, $C P K$ creatine phosphokinase
Table 3 Risk factors for in-hospital mortality

\begin{tabular}{lllr}
\hline & RR & 95\% CI & $p$ value \\
\hline Male sex & 1.135 & $0.713-1.623$ & 0.564 \\
Age (per 1 year increase) & 1.061 & $1.035-1.087$ & $<0.001$ \\
Comorbidities & & & \\
$\quad$ Diabetes & 1.559 & $1.051-2.028$ & 0.030 \\
Hypertension & 0.977 & $0.419-1.223$ & 0.927 \\
CKD & 0.891 & $0.286-1.311$ & 0.781 \\
Cardiovascular diseases & 0.916 & $0.546-1.396$ & 0.712 \\
COPD & 1.821 & $1.133-2.349$ & 0.019 \\
Laboratory features at admission & & & \\
CRP & $1.699^{*}$ & $1.364-2.070$ & $<0.001$ \\
LDH & $2.137^{*}$ & $1.654-2.679$ & $<0.001$ \\
Platelets & $0.787^{*}$ & $0.607-1.012$ & 0.075 \\
Creatinine & $1.099^{*}$ & $0.837-1.397$ & 0.562 \\
\hline
\end{tabular}

*Is intended per standard deviation increase

$R R$ relative risk, $C I$ confidence interval, $C O P D$ chronic obstructive pulmonary disease, $C K D$ chronic kidney disease, $C R P C$ reactive protein, $L D H$ lactate dehydrogenase

Table 4 Role of demographic variables and pre-existing comorbidities on the risk of in-hospital mortality

\begin{tabular}{lllr}
\hline & RR & $95 \%$ CI & \multicolumn{1}{c}{$p$ value } \\
\hline Male sex & 1.450 & $1.084-1.819$ & 0.015 \\
Age (per 1 year increase) & 1.065 & $1.029-1.086$ & $<0.001$ \\
Diabetes & 1.228 & $0.850-1.633$ & 0.253 \\
Hypertension & 1.321 & $0.909-1.806$ & 0.137 \\
CKD & 1.127 & $0.710-1.602$ & 0.580 \\
Cardiovascular diseases & 0.844 & $0.570-1.183$ & 0.348 \\
COPD & 1.449 & $0.944-1.946$ & 0.084 \\
\hline
\end{tabular}

$R R$ relative risk, $C I$ confidence interval, $C K D$ chronic kidney disease, $C O P D$ chronic obstructive pulmonary disease

that it was performed in the hospital setting and included mostly elderly patients, our results cannot be extended to all individuals with COVID-19. Finally, we were not able to collect data on the fraction of inspired oxygen patients were exposed to, and therefore could not interpret the oxygen saturation at admission, which was associated with progression to death in elderly patients in a recent study [28].

In conclusion, among patients hospitalized with COVID-19 in a single center in northern Italy, risk of in-hospital death was higher in patients with diabetes compared to non-diabetic individuals. Predictors of the primary outcome were increasing age, COPD and higher LDH and CRP values. More intensive surveillance of patients with these conditions may be warranted. 
Acknowledgements Open access funding provided by Università degli Studi di Milano - Bicocca within the CRUI-CARE Agreement.. We thank the staff of the departments of Medicine and Rehabilitation, Clinical cardiology and Anesthesiology and Intensive Care, Policlinico di Monza for their helpful assistance.

Author contributions All authors made substantial contributions to the conception and design or acquisition, analysis and interpretation of data. All authors drafted the article or revised it critically for important intellectual content. All authors approved the final version of the manuscript to be published. GP is the guarantor of this work.

Funding The authors received no specific funding for this study.

Data availability The datasets are available from the corresponding author on reasonable request.

\section{Compliance with ethical standards}

Conflict of interest No potential conflicts of interest related to this article were reported.

Ethical approval All procedures followed were in accordance with the ethical standards of the responsible committee on human experimentation (Institutional and National) and with the Helsinki Declaration of 1964 and later version.

Informed consent Informed consent was waived because of the retrospective design and the ongoing public health emergency.

Open Access This article is licensed under a Creative Commons Attribution 4.0 International License, which permits use, sharing, adaptation, distribution and reproduction in any medium or format, as long as you give appropriate credit to the original author(s) and the source, provide a link to the Creative Commons licence, and indicate if changes were made. The images or other third party material in this article are included in the article's Creative Commons licence, unless indicated otherwise in a credit line to the material. If material is not included in the article's Creative Commons licence and your intended use is not permitted by statutory regulation or exceeds the permitted use, you will need to obtain permission directly from the copyright holder. To view a copy of this licence, visit http://creativecommons.org/licenses/by/4.0/.

\section{References}

1. Gudbjartsson DF, Helgason A, Jonsson H, Magnusson OT, Melsted P, Norddahl GL, Saemundsdottir J, Sigurdsson A, Sulem P, Agustsdottir AB, Eiriksdottir B, Fridriksdottir R, Gardarsdottir EE, Georgsson G, Gretarsdottir OS, Gudmundsson KR, Gunnarsdottir TR, Gylfason A, Holm H, Jensson BO, Jonasdottir A, Jonsson F, Josefsdottir KS, Kristjansson T, Magnusdottir DN, le Roux L, Sigmundsdottir G, Sveinbjornsson G, Sveinsdottir KE, Sveinsdottir M, Thorarensen EA, Thorbjornsson B, Löve A, Masson G, Jonsdottir I, Möller AD, Gudnason T, Kristinsson KG, Thorsteinsdottir U, Stefansson K (2020) Spread of SARS-CoV-2 in the Icelandic population. N Engl J Med. https://doi.org/10.1056/ NEJMoa2006100

2. Wu Z, McGoogan JM (2020) Characteristics of and important lessons from the coronavirus disease 2019 (COVID-19) outbreak in China: summary of a report of 72314 cases from the Chinese Center for Disease Control and Prevention. JAMA 323(13):1239_ 1242. https://doi.org/10.1001/jama.2020.2648

3. Gentile S, Strollo F, Ceriello A (2020) COVID-19 infection in Italian people with diabetes: lessons learned for our future (an experience to be used). Diabetes Res Clin Pract 162:108137. https ://doi.org/10.1016/j.diabres.2020.108137

4. Dombrowski NC, Karounos DG (2013) Pathophysiology and management strategies for hyperglycemia for patients with acute illness during and following a hospital stay. Metabolism 62(3):326336. https://doi.org/10.1016/j.metabol.2012.07.020

5. Targher G, Mantovani A, Wang XB, Yan HD, Sun QF, Pan KH, Byrne CD, Zheng KI, Chen YP, Eslam M, George J, Zheng MH (2020) Patients with diabetes are at higher risk for severe illness from COVID-19. Diabetes Metab. https://doi.org/10.1016/j.diabe t.2020.05.001

6. Huang I, Lim MA, Pranata R (2020) Diabetes mellitus is associated with increased mortality and severity of disease in COVID19 pneumonia - a systematic review, meta-analysis, and metaregression. Diabetes Metab Syndr 14(4):395-403. https://doi. org/10.1016/j.dsx.2020.04.018

7. Guo W, Li M, Dong Y, Zhou H, Zhang Z, Tian C, Qin R, Wang H, Shen Y, Du K, Zhao L, Fan H, Luo S, Hu D (2020) Diabetes is a risk factor for the progression and prognosis of COVID-19. Diabetes Metab Res Rev. https://doi.org/10.1002/dmrr.3319

8. Shi Q, Zhang X, Jiang F, Zhang X, Hu N, Bimu C, Feng J, Yan S, Guan Y, Xu D, He G, Chen C, Xiong X, Liu L, Li H, Tao J, Peng Z, Wang W (2020) Clinical characteristics and risk factors for mortality of COVID-19 patients with diabetes in Wuhan, China: a two-center, retrospective study. Diabetes Care. https:// doi.org/10.2337/dc20-0598

9. Palaiodimos L, Kokkinidis DG, Li W, Karamanis D, Ognibene J, Arora S, Southern WN, Mantzoros CS (2020) Severe obesity, increasing age and male sex are independently associated with worse in-hospital outcomes, and higher in-hospital mortality, in a cohort of patients with COVID-19 in the Bronx, New York. Metab Clin Exp. https://doi.org/10.1016/j.metabol.2020.154262

10. Cummings MJ, Baldwin MR, Abrams D, Jacobson SD, Meyer BJ, Balough EM, Aaron JG, Claassen J, Rabbani LE, Hastie J, Hochman BR, Salazar-Schicchi J, Yip NH, Brodie D, O’Donnell MR (2020) Epidemiology, clinical course, and outcomes of critically ill adults with COVID-19 in New York City: a prospective cohort study. Lancet. 395(10239):1763-1770. https://doi.org/10.1016/ S0140-6736(20)31189-2

11. Sardu C, D’Onofrio N, Balestrieri ML, Barbieri M, Rizzo MR, Messina V, Maggi P, Coppola N, Paolisso G, Marfella R (2020) Outcomes in patients with hyperglycemia affected by Covid-19: can we do more on glycemic control? Diabetes Care. https://doi. org/10.2337/dc20-0723

12. D'Agostino RB (1971) An omnibus test of normality for moderate and large size samples. Biometrika 58(2):341-348. https://doi. org/10.2307/2334522

13. Zhou F, Yu T, Du R, Fan G, Liu Y, Liu Z, Xiang J, Wang Y, Song B, Gu X, Guan L, Wei Y, Li H, Wu X, Xu J, Tu S, Zhang Y, Chen H, Cao B (2020) Clinical course and risk factors for mortality of adult inpatients with COVID-19 in Wuhan, China: a retrospective cohort study. Lancet 395(10229):1054-1062. https ://doi.org/10.1016/S0140-6736(20)30566-3

14. Benjamini Y, Hochberg Y (1995) Controlling the false discovery rate: a practical and powerful approach to multiple testing. J R Stat Soc: Ser B (Methodol) 57(1):289-300

15. Zhang Y, Cui Y, Shen M, Zhang J, Liu B, Dai M, Chen L, Han D, Fan Y, Zeng Y, Li W, Lin F, Li S, Chen X, Pan P (2020) Association of diabetes mellitus with disease severity and prognosis in COVID-19: a retrospective cohort study. Diabetes Res Clin Pract. https://doi.org/10.1016/j.diabres.2020.108227 
16. Fadini GP, Morieri ML, Longato E, Avogaro A (2020) Prevalence and impact of diabetes among people infected with SARS-CoV-2. J Endocrinol Invest 43(6):867-869. https://doi.org/10.1007/s4061 8-020-01236-2

17. Chen Y, Yang D, Cheng B, Chen J, Peng A, Yang C, Liu C, Xiong M, Deng A, Zhang Y, Zheng L, Huang K (2020) Clinical characteristics and outcomes of patients with diabetes and COVID-19 in association with glucose-lowering medication. Diabetes Care. https://doi.org/10.2337/dc20-0660

18. Angelidi AM, Belanger MJ, Mantzoros CS (2020) COVID-19 and diabetes mellitus: What we know, how our patients should be treated now, and what should happen next. Metabol Clin Exp. https://doi.org/10.1016/j.metabol.2020.154245

19. Joshi N, Caputo GM, Weitekamp MR, Karchmer A (1999) Infections in patients with diabetes mellitus. N Engl J Med 341(25): 1906-1912

20. Geerlings SE, Hoepelman AI (1999) Immune dysfunction in patients with diabetes mellitus (DM). FEMS Immunol Med Microbiol 26(3-4):259-265

21. Berbudi A, Rahmadika N, Cahyadi A, Ruslami R (2019) Type 2 Diabetes and its Impact on the Immune System. Curr Diab Rep 16(5):442-449. https://doi.org/10.2174/15733998156661910240 85838

22. Chen X, Hu W, Ling J, Mo P, Zhang Y, Jiang Q, Ma Z, Cao Q, Deng L, Song S (2020) Hypertension and diabetes delay the viral clearance in COVID-19 patients. medRxiv. https://doi. org/10.1101/2020.03.22.20040774

23. Fadini GP, Morieri ML, Longato E, Bonora BM, Pinelli S, Selmin E, Voltan G, Falaguasta D, Tresso S, Costantini G, Sparacino G, Di Camillo B, Tramontan L, Cattelan AM, Vianello A, Fioretto P, Vettor R, Avogaro A (2020) Exposure to DPP-4 inhibitors and COVID-19 among people with type 2 diabetes. A case-control study. Diabetes Obes Metab. https://doi.org/10.1111/dom.14097

24. Bonnet F, Scheen AJ (2018) Effects of SGLT2 inhibitors on systemic and tissue low-grade inflammation: the potential contribution to diabetes complications and cardiovascular disease.
Diabetes Metab 44(6):457-464. https://doi.org/10.1016/j.diabe t.2018.09.005

25. Bossi AC, Forloni F, Colombelli PL (2020) Lack of efficacy of SGLT2-i in severe pneumonia related to novel coronavirus $(\mathrm{nCoV})$ infection: no little help from our friends. Diabetes Ther. https://doi.org/10.1007/s13300-020-00844-8

26. Mancia G, Rea F, Ludergnani M, Apolone G, Corrao G (2020) Renin-angiotensin-aldosterone system blockers and the risk of Covid-19. N Engl J Med. https://doi.org/10.1056/NEJMoa2006 923

27. Iaccarino G, Grassi G, Borghi C, Ferri C, Salvetti M, Volpe M, Cicero AFG, Minuz P, Muiesan ML, Mulatero P, Mulè G, Pucci G, Savoia C, Sechi L, Carugo S, Fallo F, Giannattasio C, Grassi D, Letizia C, Perlini S, Rizzoni D, Sarzani R, Tocci G, Veglio F, Rosei CA, Bevilacqua M, Bisogni V, Bombelli M, Bulfone L, Canichella F, Carpani G, Catanuso M, Chiarini G, Chiumiento F, Cianci R, Cipollini F, Concistrè A, Dalbeni A, Blasi RAD, Ciuceis CD, Dell'Oro R, Guardo AD, Lorenzo SD, Norcia MD, Ervo R, Eula E, Fabbricatore D, Fanelli E, Fava C, Grasso E, Grimaldi A, Illario M, Invernizzi C, Iraca E, Liegi F, Malerba P, Maloberti A, Mancusi C, Molinari G, Mussinelli R, Paini A, Pellimassi P, Piazza O, Pontremoli R, Tevano FQ, Rabbia F, Rocco M, Sabena A, Salinaro F, Schiavi P, Sgariglia MC, Spannella F, Tedeschi $S$, Viale $P$ (2020) Age and multimorbidity predict death among COVID-19 patients. Hypertension 76(2):366-372. https://doi. org/10.1161/HYPERTENSIONAHA.120.15324

28. Covino M, De Matteis G, Santoro M, Sabia L, Simeoni B, Candelli M, Ojetti V, Franceschi F (2020) Clinical characteristics and prognostic factors in COVID-19 patients aged $\geq 80$ years. Geriatr Gerontol Int 20(7):704-708. https://doi.org/10.1111/ggi.13960

Publisher's Note Springer Nature remains neutral with regard to jurisdictional claims in published maps and institutional affiliations. 